\title{
Inhaled treprostinil and pulmonary arterial hypertension
}

\author{
This article was published in the following Dove Press journal: \\ Vascular Health and Risk Management \\ 2 December 2010 \\ Number of times this article has been viewed
}

\author{
Samuel T Nadler \\ Jeffrey D Edelman \\ University of Washington Division \\ of Pulmonary and Critical Care \\ Medicine, Seattle, WA, USA
}

\begin{abstract}
Multiple conditions result in development of pulmonary hypertension. Pulmonary arterial hypertension (PAH) is the subclassification of pulmonary hypertension, in which known or unknown underlying conditions lead to similar intrinsic alterations in the pulmonary vasculature. PAH is a progressive condition characterized by restricted blood flow through the pulmonary circulation leading to poor survival in the absence of effective therapy. Over the last two decades, new therapeutic agents have substantially improved the course and prognosis for PAH patients. Three available classes of drugs, ie, prostacyclins, endothelin receptor antagonists, and phosphodiesterase-5 inhibitors provide multiple options for treatment of PAH. Endothelin receptor antagonists and phosphodiesterase-5 inhibitors are administered orally, whereas prostacyclin therapies are delivered by continuous intravenous or subcutaneous infusion, or as aerosols by nebulization. Because of the risks and inconveniences associated with administration, prostacyclins are typically reserved for patients with more advanced disease or progression despite oral therapy. Inhaled administration may be a safer and easier route for prostacyclin administration. Treprostinil is a prostacyclin analog that has been demonstrated to be effective when administered by continuous subcutaneous or intravenous infusion, and more recently by nebulization.
\end{abstract}

Keywords: pulmonary arterial hypertension, bosentan, prostacyclin, treprostinil, 6MWD

\section{Introduction}

Pulmonary arterial hypertension (PAH) is a progressive disease characterized by restricted blood flow through the pulmonary circulation. The current criteria for PAH include an elevated mean pulmonary artery pressure greater than $25 \mathrm{mmHg}$ at rest, with a pulmonary artery occlusion pressure less than $15 \mathrm{mmHg}$ and pulmonary vascular resistance greater than 3 Wood units. ${ }^{1}$ Elevated pulmonary arterial pressure increases the work required of the right ventricle, ultimately leading to right heart failure and death. Prior to the development of modern treatments, the one-, three-, and five-year survival rates were $68 \%, 48 \%$, and $34 \%$, respectively. ${ }^{2}$ With the development of modern therapeutic agents, these survival rates have improved to $86 \%, 69 \%$, and $61 \%$, respectively. $^{3}$

\section{Epidemiology}

Pulmonary hypertension is an uncommon disease. Recent registries in the US, Scotland, and France put the overall prevalence of PAH at $15-56$ cases per million. ${ }^{4-6}$ The recent 2008 World Health Organization (WHO) classification of pulmonary hypertension includes five general categories (Figure 1). ${ }^{7}$ The previous diagnostic
1959 NE Pacific, Campus Box 356522

Seattle, WA 98195, USA

$\mathrm{Tel}+\mathrm{I} 2065433166$

Fax +I 2066858673

Email edelmanj@u.washington.edu
Vascular Health and Risk Management 2010:6 III 5-II 24

(C) 2010 Nadler and Edelman, publisher and licensee Dove Medical Press Ltd. This is an Open Access article which permits unrestricted noncommercial use, provided the original work is properly cited. 


\begin{tabular}{|ll|}
\hline 1 & Pulmonary arterial hypertension \\
1.1 & Idiopathic \\
1.2 & Heritable \\
1.2 .1 & BMPR2 \\
1.2 .1 & ALK1, endoglin (with or without hereditary hemorrhagic telangiectasia) \\
1.2 .3 & Unknown \\
1.3 & Drug-induced and toxin-induced \\
1.4 & Associated with \\
1.4 .1 & Connective tissue disorder \\
1.4 .2 & Human immunodeficiency virus infection \\
1.4 .3 & Portal hypertension \\
1.4 .4 & Congenital heart diseases \\
1.4 .5 & Schistosomiasis \\
1.4 .6 & Chronic hemolytic anemia \\
1.5 & Persistent pulmonary hypertension of the newborn \\
1.6 & Pulmonary veno-occlusive disease and/or pulmonary capillary hemangiomatosis \\
2 & Pulmonary hypertension owing to left heart disease \\
2.1 & Systolic dysfunction \\
2.2 & Diastolic dysfunction \\
2.3 & Valvular disease \\
3 & Pulmonary hypertension owing to lung diseases and/or hypoxemia \\
3.1 & Chronic obstructive pulmonary disease \\
3.2 & Interstitial lung disease \\
3.3 & Other pulmonary diseases with mixed obstructive and restrictive pattern \\
3.4 & Sleep-disordered breathing \\
3.5 & Alveolar hypoventilation disorders \\
3.6 & Chronic exposure to high altitude \\
3.7 & Developmental abnormalities \\
4 & Chronic thromboembolic pulmonary hypertension \\
5 & Pulmonary hypertension with unclear multifactorial mechanisms \\
5.1 & Hematologic disorders, ie, myeloproliferative disorders, splenectomy \\
5.2 & Systemic disorders, ie, sarcoidosis, pulmonary Langerhans cell hystiocytosis, \\
& lymphangioleiomyomatosis, neurofibromatosis, vasculitis \\
5.3 & Metabolic disorders, including glycogen storage disease, Gaucher disease, \\
5.4 & Othyroid disorders \\
\multicolumn{2}{|c|}{ failure on dialysis } \\
\hline
\end{tabular}

Figure I Updated clinical classification of pulmonary hypertension. ${ }^{7}$

category of primary pulmonary hypertension is now referred to as idiopathic $\mathrm{PAH}$, and is included under the classification of WHO Class I or PAH. The recently published REVEAL study demonstrated that idiopathic PAH is the most prevalent form of PAH, accounting for $46.2 \%$ of patients. ${ }^{8}$ Women have a 2-3 times greater prevalence of idiopathic PAH in most registries. Although previously thought to be a disease of young women, the peak prevalence seems to occur in the fourth, fifth, and sixth decades of life. Familial forms of PAH caused by mutations in bone morphogenic protein receptor- 2 or activin-like kinase 1 represented only $2.7 \%$ of cases. Other etiologies of PAH include those associated with connective tissue disorders (25.3\%), congenital heart disease (9.8\%), liver disease (5.3\%), human immunodeficiency virus infection (1.9\%), and medication usage, including anorexigens $(5.3 \%)$. Also included in the PAH classification are pulmonary veno-occlusive disease and pulmonary capillary hemangiomatosis, which account for less than $0.5 \%$ of cases. 
Pulmonary hypertension due to left-sided heart disease, hypoxemic lung disease, and thromboembolic disorders are each classified separately. Additionally, a miscellaneous class includes sarcoidosis, pulmonary Langerhans cell histiocytosis, lymphangiomatosis, fibrosing mediastinitis, and other tumors that compress the pulmonary arteries.

While there are many conditions associated with $\mathrm{PAH}$, they share common pathophysiologic findings. $\mathrm{PAH}$ is a vasculopathy involving small arteries in the lung that regulate pulmonary blood flow. 9,10 Affected arteries demonstrate intimal hyperplasia, medial hypertrophy, adventitial proliferation, thrombosis in situ, and plexiform arteriopathy. The adventitial proliferation is thought to be due to a decreased ratio of apoptosis to proliferation of pulmonary artery smooth muscle cells. ${ }^{11}$ All contribute to narrowing of the vessel lumen, leading to increased pulmonary vascular resistance.

Endothelial dysfunction further contributes to elevated pulmonary artery resistance. Ordinarily, endothelial cells produce a balance of vasoconstrictive and vasodilatory mediators. In PAH, there is excessive production of endothelin and thromboxane, both of which are vasoconstrictors. ${ }^{12-14}$ Similarly, there is a deficit of the vasodilators, prostacyclin and nitric oxide. ${ }^{13,15}$ These molecules have become the targets of modern therapeutic interventions for PAH.

\section{Evaluation and diagnosis}

The symptoms of PAH are often nonspecific, thus a high index of suspicion is required for timely diagnosis. The most common symptoms include dyspnea (60\%) and fatigue (19\%). ${ }^{16}$ Other common symptoms include chest pain (7\%), syncope ( $8 \%$ ), lower extremity edema (3\%), and palpitations (5\%). Typical signs on physical examination suggest right ventricular strain, including an accentuated P2, jugular venous distention, a holosystolic tricuspid murmur, and an S3 or S4 heart sound. Even with these signs and symptoms, there can still be a delay of several years before a definitive diagnosis is made.

When PAH is suspected in a patient with appropriate signs and symptoms, transthoracic Doppler echocardiography is the most appropriate initial study. ${ }^{9,17}$ By measuring the tricuspid regurgitant jet, the pulmonary artery systolic pressure can be estimated. The sensitivity and specificity for detecting PAH is 0.79 to 1.00 and 0.68 to 0.98 , respectively. When a tricuspid regurgitant jet is difficult to visualize, agitated saline can be used to enhance its measurement. In studies of normal populations, only $5 \%$ of individuals have a pulmonary artery systolic pressure of greater than $37.9 \mathrm{mmHg}$, although this number increases with advanced age and obesity. ${ }^{18}$ Thus, if pulmonary artery systolic pressure is measured greater than $40 \mathrm{mmHg}$, referral for further evaluation is warranted. Echocardiography can also detect other signs of pulmonary hypertension, including right ventricular hypertrophy, right ventricular enlargement, and impaired right ventricular function.

Further testing is directed at evaluating specific conditions associated with $\mathrm{PAH}$ and excluding secondary causes of pulmonary hypertension. ${ }^{9,10}$ Chest radiography may reveal enlarged pulmonary arteries and right heart structures. Electrocardiogram may demonstrate right ventricular enlargement and strain pattern. Pulmonary function testing can evaluate for significant airflow obstruction or restriction. In the appropriate clinical settings, serologic testing for mixed connective tissue disorders, chronic liver disease, human immunodeficiency virus infection testing, and screening for obstructive sleep apnea and nocturnal hypoxia should be undertaken. Ventilation-perfusion scanning and computed tomography scanning of the chest assess for chronic thromboembolic disease and other pulmonary parenchymal diseases.

The gold standard for diagnosis of PAH is right heart catheterization. As first described by Swan and Ganz in 1970, a catheter is introduced via a central vein through the right atrium and right ventricle into the pulmonary artery, and direct measurements of pulmonary artery pressures can be obtained. ${ }^{19} \mathrm{PAH}$ is defined by a mean pulmonary artery pressure greater than $25 \mathrm{mmHg}$, with a pulmonary artery occlusion pressure less than $15 \mathrm{mmHg}$ and a calculated pulmonary vascular resistance of greater than 3 Wood units (240 dyne-sec/ $\mathrm{cm}^{5}$ ). If the mean pulmonary artery pressure is greater than $25 \mathrm{mmHg}$ but the pulmonary artery occlusion pressure is greater than $15 \mathrm{mmHg}$ or the pulmonary vascular resistance is less than 3 Wood units, then the elevated pressure in the pulmonary arteries is more likely due to elevated left atrial pressure resulting from left-sided heart disease. These patients are not classified strictly as having pulmonary arterial pressure, but rather having WHO Class II pulmonary hypertension, and therapeutics are directed at improving left ventricular heart function.

\section{Treatment}

The goals for pulmonary hypertension treatment focus on the reduction of symptoms, enhancement of exercise tolerance, normalization of hemodynamic parameters, and improvement of survival. Comprehensive evidence-based guidelines for the treatment of PAH have recently been updated., ${ }^{9,10}$ These treatments can be divided into general measures 
and agents directed specifically at the pathophysiology of PAH. Included in these medications are endothelin receptor antagonists, phosphodiesterase inhibitors, and prostacyclin analogs, such as treprostinil.

General measures are directed toward minimizing hypoxemia and volume overload states that can exacerbate PAH. Supplemental oxygen should be provided to keep measured oximetry above $90 \%$, with special attention to nocturnal hypoxemia and exposure to increased altitude/low atmospheric pressure, such as during commercial air travel. Influenza and pneumococcal vaccinations are recommended. Diuretics and a low sodium diet maintain euvolemia to prevent further right ventricular failure. Pregnancy should be avoided due to the volume expansion and increased blood flow demands normally experienced during pregnancy. In one series, the mortality associated with pregnancy in patients with pulmonary hypertension was $30 \%-56 \%{ }^{20}$ Three observational studies suggest that anticoagulation should be considered in patients with severe $\mathrm{PAH} \cdot{ }^{21-23}$ One short-term study indicated that digoxin may be beneficial in patients with low cardiac output. ${ }^{24}$

Calcium channel blockers may be used in selected individuals. During diagnostic right heart catheterization, a vasodilator trial with inhaled nitric oxide, intravenous epoprostenol, or adenosine is performed. A positive response involves a decrease in mean pulmonary artery pressure more than $10 \mathrm{mmHg}$ to a level less than $40 \mathrm{mmHg}$ and no decrement in cardiac output. Only about $10 \%$ of patients meet this criteria, and even fewer have a positive long-term response. $^{21,25}$

\section{Oral agents}

Two classes of oral agents are recommended for the treatment of mild to moderate PAH (WHO functional class II/III). ${ }^{9}{ }^{10}$ These include the endothelin receptor antagonists, bosentan, ambrisentan, and sitaxsentan, and the phosphodiesterase-5 inhibitors, sildenafil and tadalafil.

Endothelin is a 21-amino acid polypeptide first identified and isolated from cultured endothelial cells. ${ }^{26,27}$ Although it is produced primarily by endothelial cells, it is also expressed in epithelial cells, macrophages, fibroblasts, cardiomyocytes, and other tissues. ${ }^{28}$ Endothelin secretion occurs both in a constitutive fashion and in response to various stimuli, including vascular shear stress, hypoxia, and peptide mediators of inflammation. In contrast, nitric oxide, natriuretic peptides, and dilator prostanoids inhibit endothelin release. Endothelin mediates its biologic effect through two $G$ protein-coupled plasma membrane receptors, ET-A and
ET-B. ET-A is found primarily on vascular smooth muscle cells and leads to vasoconstriction, proliferation, and fibrosis. ET-B is found in endothelial cells, as well as liver, lung, and kidney tissues. Occupancy of endothelial ET-B receptors leads primarily to vasodilation and induction of nitric oxide and prostacyclin production. ET-B binding in lung, liver, and kidney parenchyma is believed to be one mechanism of clearance of endothelin. Patients with pulmonary hypertension have increased levels of endothelin, and these levels correlate with poorer outcomes. ${ }^{13,29}$ Thus, antagonism of this peptide presents a target for treatment of pulmonary hypertension.

Two endothelin receptor antagonists are currently approved by the US Food and Drug Administration for treating PAH. Bosentan is an orally available, nonpeptide endothelin receptor antagonist that blocks both ET-A and ET-B receptors. Ambrisentan is an ET-A specific receptor antagonist. Sitaxsentan is another ET-A specific antagonist, but is currently not approved for use in the US. The efficacy of these medications is the subject of a recent Cochrane review. ${ }^{30}$

Bosentan represents the first endothelin receptor antagonist for the treatment of PAH. Channick et al demonstrated in 2001 that bosentan given twice daily for at least 12 weeks to 32 patients with severe disease led to an improvement in six-minute walk distance (6MWD) of 76 meters over placebo. ${ }^{31}$ Additionally, there were improvements in cardiac output, pulmonary vascular resistance, and reduced BORG dyspnea index scores, without a significant number of adverse events. This was followed by the larger BREATHE-1 (Bosentan Randomized Trial of Endothelin Antagonist Therapy) study in 2002, in which 213 patients with severe disease received bosentan for at least 12 weeks. ${ }^{32}$ Again, patients receiving bosentan had improved 6MWD (42 meters), BORG dyspnea index, and WHO functional class. Bosentan also increased the time to clinical worsening, defined as the combined endpoint of death, lung transplantation, hospitalization for pulmonary hypertension, lack of clinical improvement, or worsening, leading to discontinuation, need for epoprostenol therapy, or atrial septostomy. Subsequently, several longer-term studies, up to three years in duration, have demonstrated a significant survival benefit of bosentan compared with historic controls. ${ }^{33,34}$ Patients taking bosentan had survival rates of $92 \%, 89 \%$, and $79 \%$ at years 1,2 , and 3 , respectively, compared with expected survival of $71 \%, 61 \%$, and 51\%. In 2008, Galie et al demonstrated that bosentan benefited patients with milder, WHO functional class II disease. ${ }^{35}$ These studies demonstrated the most common adverse effect was an elevation in hepatic enzymes that 
was thought to be due to ET-B receptor antagonism leading to decreased clearance. This led to the development of the ET-A specific agents, sitaxsentan and ambrisentan.

Sitaxsentan was the first ET-A specific receptor antagonist for the treatment of PAH. It has about 6500 times greater affinity for ET-A than for ET-B receptors. ${ }^{36}$ The STRIDE-1 (Sitaxsentan To Relieve Impaired Exercise) study examined the safety and efficacy of sitaxsentan in 118 patients over a 12 -week period. ${ }^{37}$ Although a secondary endpoint, there was an improvement in 6MWD of 35 and 33 meters with daily administration of $100 \mathrm{mg}$ and $300 \mathrm{mg}$ of sitaxsentan, respectively. However, elevations in hepatic aminotransferases were observed in $10 \%$ of the $300 \mathrm{mg}$ group compared with $3 \%$ for the placebo arm. The STRIDE-2 study examined the effects of lower doses of sitaxsentan, from $50 \mathrm{mg}$ to $100 \mathrm{mg} .{ }^{38}$ Again, improvements in 6MWD of 24.2 and 31.4 meters were seen for $50 \mathrm{mg}$ and $100 \mathrm{mg}$ doses, respectively. The rates of elevated hepatic aminotransferases were similar to placebo ( $3 \%-5 \%$ versus $6 \%$ ). An extension of the STRIDE-1 in 11 patients for one year demonstrated that $100 \mathrm{mg}$ of sitaxsentan daily led to a sustained improvement in 6MWD of 50 meters, improved functional class, and hemodynamics compared with baseline. ${ }^{39}$ There were no reports of hepatotoxicity in this study.

Ambrisentan is an oral, nonsulfonamide ET-A selective receptor antagonist with a half-life of 9-15 hours, allowing once-daily dosing. The safety and efficacy of ambrisentan was first shown in 2005. ${ }^{40}$ In 64 patients with PAH, daily administration of ambrisentan led to an improvement of 6MWD of 36.1 meters, improved dyspnea, WHO functional class, and cardiopulmonary hemodynamics. Subsequently, the larger ARIES-1 and 2 studies demonstrated improved 6MWD, dyspnea scores, and time to clinical worsening in 202 and 192 patients, respectively. ${ }^{41}$ Neither of these studies showed an elevation in liver enzymes greater than three times the upper limit of normal. However, peripheral edema was observed to a greater extent in patients taking ambrisentan. An extension of the ARIES study showed improved 6MWD in 280 patients after 48 weeks of treatment.

The phosphodiesterase inhibitors, sildenafil and tadalafil, represent the second class of oral agents for the treatment of PAH. In the lung, nitric oxide acts as an important vasodilator via stimulation of cyclic guanidine monophosphate (cGMP) synthesis. Cyclic GMP activates protein kinase G, which mediates lower intracellular calcium in vascular smooth muscle and facilitates vascular relaxation, antiproliferation, and apoptosis. ${ }^{42}$ Phosphodiesterase- 5 hydrolyzes cGMP, which prevents protein kinase $\mathrm{G}$ activation and its downstream effects. In PAH, there is increased expression of phosphodiesterase-5 in the lung and decreased expression of nitric oxide synthase. ${ }^{43,44}$ Both the reduction in cGMP production and its increased hydrolysis lead to pulmonary smooth muscle vasoconstriction and proliferation. Antagonism of phosphodiesterase-5 with either sildenafil or tadalafil increases cGMP levels, leading to relaxation of pulmonary vascular smooth muscle and decreased pulmonary vascular resistance.

The safety and efficacy of sildenafil for the treatment of PAH was demonstrated in the SUPER (Sildenafil Use in Pulmonary Arterial Hypertension) trial. ${ }^{45}$ Published in 2005, this was a double-blind, placebo-controlled study of 278 patients with symptomatic PAH sponsored by Pfizer. During 12 weeks of treatment with $20 \mathrm{mg}, 40 \mathrm{mg}$, or $80 \mathrm{mg}$ three times daily, sildenafil treatment led to improvements in 6MWD of 45, 46, and 50 meters, respectively. At all doses, mean pulmonary artery pressure was decreased and WHO functional class was improved. A follow-up study of 222 patients who continued to take $80 \mathrm{mg}$ of sildenafil showed an improved 6MWD of 51 meters after one year of treatment. Additionally, health-related quality of life measurements also improved with sildenafil treatment at 24 weeks. ${ }^{46}$

Tadalafil is a once-daily dosed selective inhibitor of phosphodiesterase-5. Previously approved for erectile dysfunction, the utility of tadalafil in PAH was demonstrated by the PHIRST (Pulmonary Arterial Hypertension and Response to Tadalafil) study. ${ }^{47}$ In this 16 -week, double-blind, randomized, placebo-controlled study sponsored by Eli Lilly, 405 patients received varied doses of tadalafil or placebo. Tadalafil lead to improvements in 6MWD in a dose-dependent fashion. Although there was no improvement in WHO functional class, the time to clinical worsening was longer with tadalafil $40 \mathrm{mg}$ daily. At the highest doses, tadalafil treatment also improved cardiac output and reduced pulmonary vascular resistance.

\section{Prostacyclin analogs}

Prostacyclin is an endogenous vasodilator produced by prostacyclin synthase in endothelial cells of the pulmonary vasculature. Prostacyclin acts locally to promote vasodilation and reduce pulmonary vascular resistance. In PAH, there is imbalance between this vasodilator and other vasoconstrictor molecules, with decreased expression of prostacyclin synthase and increased levels of thromboxane A2. ${ }^{12,15}$ In addition to vasodilation, prostacyclin has an antiproliferative effect on smooth muscle cells in vitro. ${ }^{48}$ Abnormal levels of prostacyclin facilitate the medial hypertrophy seen in $\mathrm{PAH}$. 
Furthermore, prostacyclin prevents platelet activation and aggregation by thromboxane A2. ${ }^{49}$ Reduced levels of prostacyclin allow for thrombosis in situ also seen in PAH. Thus, pharmacologic restoration of prostacyclin levels would prevent the vasoconstriction, smooth muscle cell proliferation, thrombosis in situ, and plexiform arteriopathy that are hallmarks of PAH.

Three prostacyclin analogs are approved for the treatment of PAH in the US, ie, epoprostenol, treprostinil, and iloprost (Figure 2). Beraprost is not currently approved by the Food and Drug Administration. Epoprostenol was the first prostacyclin approved for the treatment of PAH. Due to its short half life ( $<$ six minutes) and poor stability at $\mathrm{pH}<10.5$, epoprostenol must be refrigerated for storage and administered as a continuous infusion through a central venous catheter. These limitations led to the development of the tricyclic benzidine prostacyclin, treprostinil. Treprostinil may be given either as a continuous intravenous or subcutaneous infusion with similar bioavailability. ${ }^{50}$ The half-life of treprostinil is 4.4 and 4.6 hours by intravenous and subcutaneous infusion, respectively. More recently, an inhaled form has become available with four times daily dosing. Iloprost also may be inhaled, as often as 6-9 times per day due to its short half-life (20-30 minutes).

Three seminal studies have demonstrated the clinical effectiveness of epoprostenol for PAH. ${ }^{51-53}$ In 81 patients with functional class III/IV primary pulmonary hypertension, Barst et al demonstrated that epoprostenol infusion improved 6MWD, mean pulmonary artery pressure, pulmonary vascular resistance, and survival. However, four episodes of catheter-related sepsis and one thrombotic event were noted. ${ }^{53}$ Subsequently, McLaughlin et al demonstrated that epoprostenol therapy not only improved hemody-

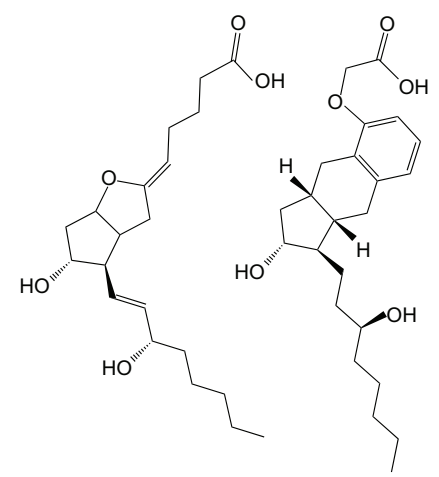

Epoprostenol

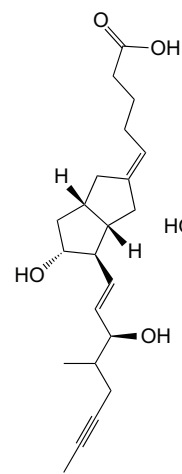

lloprost

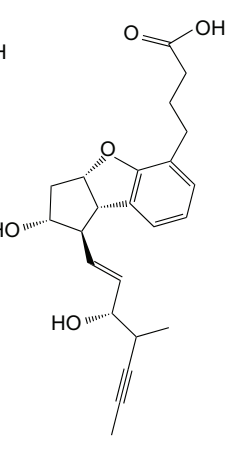

Beraprost
Figure 2 Chemical stuctures of epoprostenol, treprostinil, iloprost and beraprost. namic parameters, but also improved survival over a mean 36.1-month follow-up period in 162 patients compared with historic controls. ${ }^{51}$ Sitbon et al similarly demonstrated a survival benefit of intravenous epoprostenol therapy in a separate study of 178 patients with moderate to severe $\mathrm{PAH} .{ }^{52}$ Badesch et al extended the utility of epoprostenol beyond patients with primary pulmonary hypertension in 2000 . In 111 patients with pulmonary hypertension due to scleroderma, epoprostenol improved pulmonary vascular hemodynamics and exercise capacity over a 12 -week treatment course. ${ }^{54}$ In addition, nonrandomized studies have suggested that epoprostenol treatment may be effective in patients with $\mathrm{PAH}$ due to congenital left-to-right shunts, portopulmonary hypertension, and human immunodeficiency virus infection. ${ }^{55-58}$

The pharmacodynamics of treprostinil were recently reviewed in this journal. ${ }^{59}$ Unlike epoprostenol, treprostinil is chemically stable at room temperature and at neutral $\mathrm{pH}$. This facilitates its use in both intravenous and subcutaneous infusion. Simonneau et al evaluated the efficacy of continuous subcutaneous treprostinil in 470 patients over a 12 -week period. ${ }^{60}$ In this study, 6MWD improved in a dose-dependent fashion, as did dyspnea indices and hemodynamics. Infusion site pain and reactions were common, complicating therapy in $85 \%$ and $83 \%$ of patients, respectively. The effects of long-term subcutaneous treprostinil were separately examined in 99 patients with $\mathrm{PAH}$ and 23 patients with chronic thromboembolic pulmonary hypertension. ${ }^{61}$ After a mean follow-up of 26.2 months, patients treated with subcutaneous treprostinil demonstrated increased 6MWD as well as improved dyspnea score, functional class, and overall survival. Barst et al followed 806 patients for up to four years on subcutaneous treprostinil therapy and demonstrated improved survival versus historic controls. ${ }^{62}$ Of the 196 patients who discontinued the medication, 34\% stopped within the first year of treatment due to infusion site pain. Intravenous treprostinil therapy was studied in a 12-week, open-label study in 16 patients with PAH. ${ }^{63}$ Continuous intravenous treprostinil improved 6MWD (82 meters compared with baseline), hemodynamics, and BORG dyspnea score.

Iloprost is an inhaled carbacyclin prostacyclin analog used to treat pulmonary hypertension. ${ }^{64}$ Early studies comparing inhaled epoprostenol and iloprost demonstrated short-term efficacy of both agents, but iloprost had a significantly longer duration of action (10-30 minutes versus 60-120 minutes). ${ }^{65}$ In an uncontrolled trial, Olschewksi et al demonstrated the benefit of inhaled iloprost nebulized 6-12 times daily over the course of three months. ${ }^{66}$ A large, randomized 
controlled study of iloprost confirmed this benefit. ${ }^{67}$ Over a period of 12 weeks, patients treated with inhaled iloprost six or nine times daily demonstrated increased 6MWD (36.4 meters), improved hemodynamics, and functional class. In this study, syncope, flushing, and cough significantly increased with inhaled iloprost. The long-term efficacy of inhaled iloprost was studied in 24 patients over the course of one year. ${ }^{68}$ Patients had a sustained improvement in 6MWD, cardiac output, and pulmonary vascular resistance. However, in a separate study, after 12 months, only 32 of 76 patients were stabilized on iloprost monotherapy, most requiring additional therapy (23 patients) or transplant (two patients). ${ }^{69}$

Beraprost is a stable, cyclopentabenzofuranyl prostacyclin analog that enables oral administration. ALPHABET (Arterial Pulmonary Hypertension and Beraprost European Trial) was a randomized, placebo-controlled study of 130 patients with PAH over 12 weeks. ${ }^{70}$ Beraprost administered at a dose of up to $120 \mu \mathrm{g}$ four times daily improved exercise capacity in patients with idiopathic PAH although it did not significantly alter the hemodynamic outcomes measured. Headache, flushing, jaw pain, diarrhea, and nausea were frequent during the titration period but were less common in the maintenance phase. In contrast, Barst et al failed to demonstrate sustained improvement in exercise tolerance or disease progression in 116 patients with WHO functional class II or III PAH due to collagen vascular disease or congenital heart disease. ${ }^{71}$ A retrospective study of 58 patients with idiopathic $\mathrm{PAH}$ demonstrated a three-year survival rate of $76 \%$ compared with $44 \%$ with conventional therapy. ${ }^{72}$ Beraprost is currently approved for treatment of PAH in Japan.

\section{Inhaled treprostinil}

The difficulty with injection site pain and potential pharmacologic benefits of inhaled therapy led to the development of aerosolized treprostinil therapy for PAH. Initial investigations compared the effects of inhaled and intravenous treprostinil in sheep with PAH induced by 9,11-dideoxy-9, 11-epoxymethanoprostaglandin $\mathrm{F}_{2}$ (U44069), a $\mathrm{PGH}_{2}$ ana$\log$ that led to a four-fold increase in pulmonary vascular resistance. ${ }^{73}$ Both inhaled and intravenous treprostinil reversed this effect in a dose-dependent fashion. However, only inhaled treprostinil at $1000 \mathrm{ng} / \mathrm{kg} / \mathrm{min}$ fully reversed the pulmonary arterial vasoconstriction and normalized pulmonary artery pressures. At this dose, there was no significant change in systemic blood pressure, cardiac output, or heart rate. The duration of effect of inhaled treprostinil was about three times greater than that of inhaled epoprostenol, thereby demonstrating the efficacy of inhaled treprostinil in an animal model of PAH.

The first published trial of inhaled treprostinil in humans characterized its effects in three patients with severe PAH. ${ }^{74}$ After right heart catheterization, each patient received a single administration of $15 \mu \mathrm{g}$ of treprostinil in three breaths through an ultrasonic inhalation device. This single dose reduced pulmonary vascular resistance by $45.2 \% \pm 17.5 \%$, with sustained effects observed for longer than 180 minutes after inhalation. Subsequently, two patients continued on inhaled treprostinil therapy, $15 \mu \mathrm{g}$ four times daily, on a compassionate treatment basis. After three months, both had improvement in functional class and 6MWD.

Further studies in humans compared inhaled treprostinil with iloprost. Voswinckel et al compared the effects of these medications in 123 patients with different forms of PAH. ${ }^{75}$ Administration of either medication led to a rapid decrease in pulmonary vascular resistance and pulmonary artery pressure. A comparison of three inhaled treprostinil regimens, ie, $7.5 \mu \mathrm{g}$ over six minutes, $15 \mu \mathrm{g}$ over six minutes, or $15 \mu \mathrm{g}$ over three minutes, showed no significant difference in pulmonary vascular resistance reduction. When compared with iloprost, the maximum effect of inhaled treprostinil was comparable. However, the peak effect of iloprost ( $8 \pm 1$ minutes) was observed more quickly than for inhaled treprostinil (18 \pm 2 minutes), while the inhaled treprostinil led to a more prolonged effect extending beyond the three-hour experimental window. Peak plasma treprostinil levels were observed 10-15 minutes after inhalation, consistent with the drug's peak effect. In this small study, the most common side effects of treprostinil were cough (six of 48 patients), headache (two of 48 patients), and jaw pain (1 of 48 patients).

Additional clinical trials have been performed to evaluate the combination of inhaled treprostinil with other PAH therapies. In a 12-week, open-label safety and efficacy trial, 12 patients with PAH and functional class III or IV symptoms despite oral bosentan administration received additional inhaled treprostinil. ${ }^{76}$ Two dosing regimens were used, ie, $30 \mu \mathrm{g}$ (six inhalations) four times daily and $45 \mu \mathrm{g}$ (nine inhalations) four times daily, via a hand-held ultrasonic, singlebreath nebulizer. Acutely, the effect of inhaled treprostinil peaked at 45 minutes and returned to baseline by 180 minutes. After 12 weeks of therapy, significant reductions in mean pulmonary artery pressure and pulmonary vascular resistance were observed at peak post-inhalation, with a trend toward 
improvement in cardiac output. Notably, both pre- and post-inhalation 6MWD was improved with therapy.

The acute effects of the combination of sildenafil and inhaled treprostinil have also been studied. ${ }^{77}$ Fifty patients with moderate to severe pulmonary hypertension received sildenafil plus $15 \mu \mathrm{g}$ or $30 \mu \mathrm{g}$ inhaled treprostinil. Inhaled treprostinil induced a significant reduction in pulmonary vascular resistance and pulmonary arterial pressure beyond the treatment effect from sildenafil alone that was present up to two hours after inhalation. While the $15 \mu \mathrm{g}$ and $30 \mu \mathrm{g}$ doses were equally effective, the $30 \mu \mathrm{g}$ dose had a longer duration of action. Interestingly, a subgroup analysis of patients with either PAH or chronic thromboembolic pulmonary hypertension demonstrated similar results. Approximately 10\% of patients reported a cough, but the known side effects of sildenafil including headache, musculoskeletal pain, dizziness, and hypotension, were not potentiated by treprostinil inhalation. Also, ventilation/perfusion matching was not significantly altered by treprostinil administration.

Recently, a metered dose inhaler (MDI) formulation of treprostinil was evaluated. ${ }^{78}$ This device has the advantages of a smaller size and improved ease of use compared with the ultrasonic nebulizer. The aerodynamic aerosol diameter of MDI treprostinil is 4-5 $\mu \mathrm{m}$, which is at the upper size limit for alveolar deposition. Doses of $30 \mu \mathrm{g}, 45 \mu \mathrm{g}$, or $60 \mu \mathrm{g}$ of MDI treprostinil lowered mean pulmonary artery pressure and pulmonary vascular resistance. Pulmonary vasodilation extended beyond the observation period of two hours. Pulmonary vascular resistance reduction by MDI was comparable with that previously observed with ultrasonic nebulizer. There was no observed decrease in ventilation/ perfusion matching by treprostinil delivered by MDI.

Currently, treprostinil is delivered using an ultrasonic pulse-delivery nebulizer system. ${ }^{79}$ Initial dosing begins at three breaths or $18 \mu \mathrm{g}$ four times daily, and may be increased at 1-2-week intervals up to a maximum dose of nine breaths (54 $\mu \mathrm{g}$ ) four times daily. Cough, headache, throat irritation, nausea, and flushing are common side effects of inhaled treprostinil.

\section{Conclusion}

The number of available treatments for PAH continues to increase. Three classes of drugs, ie, prostacyclins, endothelin receptor antagonists, and phosphodiesterase-5 inhibitors, affecting different mechanisms involved in the pathogenesis of PAH, are currently available. Endothelin receptor antagonists and phosphodiesterase-5 inhibitors are administered orally at a frequency that varies from once to three times daily. Prostacyclin therapies are delivered by continuous intravenous infusion (epoprostenol and treprostinil), by continuous subcutaneous infusion (treprostinil), or as aerosols by nebulization (iloprost and treprostinil). Typically, oral therapies are utilized for patients with milder disease, whereas the prostacyclins are initiated in patients with more advanced disease, or progression despite oral therapy. The use of inhaled agents reduces the risks and inconveniences associated with infused treatments, and further expand the potential role for prostacyclin therapies. Continued experience and evaluation of inhaled treprostinil, particularly in combination with oral therapies, will help to provide further assessment of its long-term safety and efficacy.

\section{Disclosure}

The authors report no conflicts of interest in this work.

\section{References}

1. Hoeper M. Definition, classification and epidemiology of pulmonary arterial hypertension. Semin Respir Crit Care Med. 2009;30:369-375.

2. D'Alonzo GF, Barst RJ, Ayres SM, et al. Survival in patients with primary pulmonary hypertension. Ann Intern Med. 1991;115:343-349.

3. Thenappan T, Shah S, Rich S, Tian L, Archer S, Gomberg-Maitland M. Contemporary survival in patients with pulmonary arterial hypertension: A reappraisal of the NIH risk stratification equation. Eur Respir J. 2010;35:1079-1087.

4. Humbert M, Sitbon O, Chaouat A, et al. Pulmonary arterial hypertension in France: Results from a national registry. Am J Respir Crit Care Med. 2006;173:1023-1030.

5. Peacock A, Murphy N, McMurray J, Caballero L, Stewart S. An epidemiological study of pulmonary arterial hypertension. Eur Respir $J$. 2007;30:104-109.

6. Thenappan T, Shah S, Rich S, Gomberg-Maitland M. A USA-based registry for pulmonary arterial hypertension: 1982-2006. Eur Respir J. 2007;30:1103-1110.

7. Simmoneau G, Robbins I, Beghetti M, et al. Updated clinical classification of pulmonary hypertension. J Am Coll Cardiol. 2009;54:S43-S54.

8. Badesch D, Raskob G, Elliott C, et al. Pulmonary arterial hypertension - baseline characteristics from the REVEAL registry. Chest. 2010;137:376-387.

9. McLaughlin V, Archer S, Badesch D, et al. ACCF/AHA 2009 expert consensus document on pulmonary hypertension. Circulation. 2009; 119:2250-2294

10. Galie N, Hoeper M, Humbert M, et al. Guidelines for the diagnosis and treatment of pulmonary hypertension. Eur Respir J. 2009;34: $1219-1263$.

11. Farber H, Loscalzo J. Pulmonary arterial hypertension. N Engl J Med. 2004;351:1655-1665.

12. Christman B, McPherson C, Newman J, et al. An imbalance between the excretion of thromboxane and prostacyclin metabolites in pulmonary hypertension. N Engl J Med. 1992;327:70-75.

13. Giaid A, Yanagisawa M, Langleben D, et al. Expression of endothelin-1 in the lungs of patients with pulmonary hypertension. $N$ Engl $J$ Med. 1993;328:1732-1739.

14. Stewart D, Levy R, Cernacek P, Langleben D. Increased plasma endothelin-1 in pulmonary hypertension: Marker or mediator of disease? Ann Intern Med. 1991;114:464-469.

15. Tuder R, Cool C, Geraci M, et al. Prostacyclin synthase expression is decreased in lungs from patients with severe pulmonary hypertension. Am J Respir Crit Care Med. 1999;159:1925-1932. 
16. Rich S, Dantzker D, Ayres S, et al. Primary pulmonary hypertension - a national prospective study. Ann Intern Med. 1987;107:216-223.

17. McGoon M, Gutterman D, Steen V, et al. Screening, early detection and diagnosis of pulmonary arterial hypertension. Chest. 2004;126 Suppl 1: $14 \mathrm{~S}-34 \mathrm{~S}$.

18. McQuillan B, Picard M, Leavitt M, Weyman A. Clinical correlates and reference intervals for pulmonary artery systolic pressure among echocardiographically normal subjects. Circulation. 2001;104: 2797-2802.

19. Swan H, Ganz W, Forrester J, Marcu H, Diamond G, Chonette D. Catheterization of the heart in man with use of a flow-directed balloontipped catheter. N Engl J Med. 1970;283:447-451.

20. Weiss B, Zemp L, Seifert B, Hess O. Outcome of pulmonary vascular disease in pregnancy: A systematic overview from 1978 through 1996. J Am Coll Cardiol. 1998;31:1650-1657.

21. Rich S, Kaufman E, Levy P. The effect of high doses of calcium-channel blockers on survival in primary pulmonary hypertension. $N$ Engl J Med. 1992;327:76-81.

22. Frank H, Mlczoch J, Huber K, Schuster E, Gurtner H, Kneussl M. The effect of anticoagulant therapy in primary and anorectic drug-induced pulmonary hypertension. Chest. 1997;112:714-721.

23. Fuster V, Steele P, Edwards W, Gersh B, McGoon M, Frye R. Primary pulmonary hypertension: Natural history and the importance of thrombosis. Circulation. 1984;70:580-587.

24. Rich S, Seidlitz M, Dodin E, et al. The short-term effects of digoxin in patients with right ventricular dysfunction from pulmonary hypertension. Chest. 1998;114:787-792.

25. Sitbon O, Humbert M, Jais X, et al. Long-term response to calcium channel blockers in idiopathic pulmonary arterial hypertension. Circulation. 2005;111:3105-3111.

26. Hickey K, Rubanyi G, Paul R, Highsmith R. Characterization of a coronary vasoconstrictor produced by cultured endothelial cells. $\mathrm{Am} \mathrm{J}$ Physiol. 1985;248:C550-556.

27. Yanagisawa M, Kurihara H, Kimura S, et al. A novel potent vasoconstrictor peptide produced by vascular endothelial cells. Nature. 1988; 332:411-415.

28. Kedzierski R, Yanagisawa M. Endothelin system: The doubleedged sword in health and disease. Annu Rev Pharmacol Toxicol. 2001;41:851-876.

29. Rubens C, Ewert R, Halank M, et al. Big endothelin-1 and endothelin-1 plasma levels are correlated with the severity of primary pulmonary hypertension. Chest. 2001;120:1562-1569.

30. Liu C, Chen J, Gao Y, Deng B, Liu K. Endothelin receptor antagonists for pulmonary arterial hypertension. Cochrane Database Syst Rev. 2009;3:CD004434.

31. Channick R, Simonneau G, Sitbon O, et al. Effects of the dual endothelin-receptor antagonist bosentan in patients with pulmonary hypertension: A randomised placebo controlled study. Lancet. 2001, 358:1119-1123.

32. Rubin L, Badesch D, Barst R, et al. Bosentan therapy for pulmonary arterial hypertension. N Engl J Med. 2002;346:896-903.

33. McLaughlin V, Sitbon O, Badesch B, et al. Survival with first-line bosentan in patients with primary pulmonary hypertension. Eur Respir J. 2005;25:244-249.

34. Provencher S, Sitbon O, Humbert M, Cabrol S, Jais X, Simonneau G. Long-term outcome with first-line bosentan therapy in idiopathic pulmonary arterial hypertension. Eur Heart J. 2006;27:589-595.

35. Galie N, Rubin L, Hal-Hiti P, et al. Treatment of patients with mildly symptomatic pulmonary arterial hypertension with bosentan (EARLY study): A double-blind, randomised controlled trial. Lancet. 2008;371:2093-2100.

36. Wu C, Chan M, Stavros F, et al. Discovery of TBC11251, a potent, long acting, orally active endothelin receptor-a selective antagonist. J Med Chem. 1997;40:1690-1697.

37. Barst R, Langleben D, Frost A, et al. Sitaxsentan therapy for pulmonary arterial hypertension. Am J Respir Crit Care Med. 2004;169: 441-447.
38. Barst R, Langleben D, Badesch D, et al. Treatment of pulmonary arterial hypertension with the selective endothelin-a receptor antagonist sitaxsentan. J Am Coll Cardiol. 2006;47:2049-2056.

39. Langleben D, Hirsch A, Shalit E, Lezenko L, Barst R. Sustained symptomatic, functional, and hemodynamic benefit with the selective endothelin-a receptor antagonist, sitaxsentan, in patients with pulmonary arterial hypertension. Chest. 2004;126:1377-1381.

40. Galie N, Badesch D, Oudiz R, et al. Ambrisentan therapy for pulmonary arterial hypertension. J Am Coll Cardiol. 2005;46:529-535.

41. Galie N, Olschewski H, Oudiz R, et al. Ambrisentan for the treatment of pulmonary arterial hypertension. Circulation. 2008;117:3010-3019.

42. Archer S, Michelakis E. Phosphodiesterase type 5 inhibitors for pulmonary arterial hypertension. N Engl J Med. 2009;361:1864-1871.

43. Giaid A, Saleh D. Reduced expression of endothelial nitric oxide synthase in the lungs of patients with pulmonary hypertension. $N$ Engl J Med. 1995;333:214-221.

44. Murray F, MacLean M, Pyne N. Increased expression of the cGMPinhibited cAMP-specific (PDE3) and cGMP binding cGMP-specific (PDE5) phosphodiesterases in models of pulmonary hypertension. $\mathrm{Br} J$ Pharmacol. 2002;137:1187-1194.

45. Galie N, Ghofrani H, Torbicki A, et al. Sildenafil citrate therapy for pulmonary arterial hypertension. $N$ Engl J Med. 2005;353: 2148-2157.

46. Pepke-Zaba J, Gilbert C, Collings L, Brown M. Sildenafil improves health-related quality of life in patients with pulmonary arterial hypertension. Chest. 2008;133:183-189.

47. Galie N, Brundage B, Ghofrani H, et al. Tadalafil therapy for pulmonary arterial hypertension. Circulation. 2009;119:2894-2903.

48. Zucker T, Bunisch D, Hasse A, Grosser T, Weber A, Schror K. Tolerance development to antimitogenic actions of prostacyclin but not of prostaglandin E1 in coronary artery smooth muscle cells. Eur $J$ Pharmacol. 1998;345:213-220.

49. Cheng Y, Austin S, Rocca B, et al. Role of prostacyclin in the cardiovascular response to thromboxane A2. Science. 2002;296:539-541.

50. Laliberte K, Arneson C, Jeffs R, Hunt T, Wade M. Pharmacokinetics and steady-state bioequivalence of treprostinil sodium (Remodulin) administered by the intravenous and subcutaneous route to normal volunteers. J Cardiovasc Pharmacol. 2004;44:209-214.

51. McLaughlin V, Shilington A, Rich S. Survival in primary pulmonary hypertension: The impact of epoprostenol therapy. Circulation. 2002; 106:1477-1482.

52. Sitbon O, Humbert M, Nunes $\mathrm{H}$, et al. Long-term intravenous epoprostenol infusion in primary pulmonary hypertension. $\mathrm{J} \mathrm{Am} \mathrm{Coll} \mathrm{Cardiol}$. 2002;40:780-788.

53. Barst R, Rubin L, Long W, et al. A comparison of continuous intravenous epoprostenol (prostacyclin) with conventional therapy for primary pulmonary hypertension. N Engl J Med. 1996;334:296-301.

54. Badesch D, Tapson V, McGoon M, et al. Continuous intravenous epoprostenol for pulmonary hypertension due to the scleroderma spectrum of disease. Ann Intern Med. 2000;132:425-434.

55. Aguilar R, Farber H. Epoprostenol (prostacyclin) therapy in HIVassociated pulmonary hypertension. Am J Respir Crit Care Med. 2000; 162:1846-1850.

56. Plotkin J, Kuo P, Rubin L, et al. Successful use of chronic epoprostenol as a bridge to liver transplantation in severe portopulmonary hypertension. Transplantation. 1998;4:457-459.

57. Tan H, Markowitz J, Montgomery R, et al. Liver transplantation in patients with severe portopulmonary hypertension treated with preoperative chronic intravenous epoprostenol. Liver Transpl. 2001;7:745-749.

58. Rosenzweig E, Kerstein D, Barst R. Long-term prostacyclin for pulmonary hypertension with associated congenital heart defects. Circulation. 1999;99:1858-1865.

59. Skoro-Sajer N, Lang I, Naeije R. Treprostinil for pulmonary hypertension. Vasc Health Risk Manag. 2008;4:507-513.

60. Simonneau G, Barst R, Galie N, et al. Continuous subcutaneous infusion of treprostinil, a prostacyclin analogue, in patients with pulmonary arterial hypertension. Am J Respir Crit Care Med. 2002;165:800-804. 
61. Lang I, Gomez-Sanchez M, Kneussl M, et al. Efficacy of long-term subcutaneous treprostinil sodium therapy in pulmonary hypertension. Chest. 2006;129:1636-1643.

62. Barst R, Galie N, Simonneau G, Jeffs R, Arneson C, Rubin L. Longterm outcome in pulmonary arterial hypertension patients treated with subcutaneous treprostinil. Eur Heart J. 2006;28:1195-1203.

63. Tapson V, Gomberg-Maitland M, McLaughlin V, et al. Safety and efficacy of IV treprostinil for pulmonary arterial hypertension. Chest. 2006;129:683-688.

64. Krug S, Sablotzki A, Hammerschmidt S, Wirtz H, Seyfarth H. Inhaled iloprost for the control of pulmonary hypertension. Vasc Health Risk Manag. 2009;5:465-474.

65. Olschewski H, Walmrath D, Schermuly R, Ghofrani A, Grimminger F, Seeger W. Aerosolized prostacyclin and iloprost in severe pulmonary hypertension. Ann Intern Med. 1996;124:820-824.

66. Olschewski H, Ghofrani A, Schmehl T, et al. Inhaled iloprost to treat severe pulmonary hypertension. Ann Intern Med. 2000;132:435-443.

67. Olschewski H, Simonneau G, Galie N, et al. Inhaled iloprost for severe pulmonary hypertension. $N$ Engl J Med. 2002;347:322-329.

68. Hoeper M, Schwarze M, Ehlerding S, et al. Long-term treatment of primary pulmonary hypertension with aerosolized iloprost, a prostacyclin analogue. $N$ Engl J Med. 2000;342:1866-1870.

69. Opitz C, Wensel R, Winkler J, et al. Clinical efficacy and survival with first-line inhaled iloprost therapy in patients with idiopathic pulmonary arterial hypertension. Eur Heart J. 2005;26:1895-1902.

70. Galie N, Humbert M, Vachiery J, et al. Effects of beraprost sodium, an oral prostacyclin analogue, in patients with pulmonary arterial hypertension: A randomized, double-blind, placebo controlled trial. J Am Coll Cardiol. 2002;39:1496-1502.
71. Barst R, McGoon M, McLaughlin V, et al. Beraprost therapy for pulmonary arterial hypertension. J Am Coll Cardiol. 2003;41: 2119-2125.

72. Nagaya N, Uematsu M, Okano Y, et al. Effect of orally active prostacyclin analogue on survival of outpatients with primary pulmonary hypertension. J Am Coll Cardiol. 1999;34:1188-1192.

73. Sandifer B, Brigham K, Lawrence E, Mottola D, Cuppels C, Parker R. Potent effects of aerosol compared with intravenous treprostinil on the pulmonary circulation. J Appl Physiol. 2005;99:2363-2368.

74. Voswinckel R, Ghofrani H, Grimminger F, Seeger W. Inhaled treprostinil for treatment of chronic pulmonary arterial hypertension. Ann Intern Med. 2006;144:149-150.

75. Voswinckel R, Enke B, Reichenberger R, et al. Favorable effects of inhaled treprostinil in severe pulmonary hypertension: Results from randomized controlled pilot studies. J Am Coll Cardiol. 2006;48: 1672-1681.

76. Channick R, Olschewski H, Seeger W, Staub T, Voswinckel R, Rubin L. Safety and efficacy of inhaled treprostinil as add-on therapy to bosentan in pulmonary arterial hypertension. J Am Coll Cardiol. 2006;48:1433-1437.

77. Voswinckel H, Reichenberger F, Enke B, et al. Acute effects of the combination of sildenafil and inhaled treprostinil on haemodynamics and gas exchange in pulmonary hypertension. Pulm Pharmacol Ther. 2008;21:824-832.

78. Voswinckel R, Reichenberger F, Gall H, et al. Metered dose inhaler delivery of treprostinil for the treatment of pulmonary hypertension. Pulm Pharmacol Ther. 2009;22:50-56.

79. Tyvaso Prescribing Information. Research Triangle Park, NC: United Therapeutics Corp; 2010.
Vascular Health and Risk Management

\section{Publish your work in this journal}

Vascular Health and Risk Management is an international, peerreviewed journal of therapeutics and risk management, focusing on concise rapid reporting of clinical studies on the processes involved in the maintenance of vascular health; the monitoring, prevention and treatment of vascular disease and its sequelae; and the involvement of

\section{Dovepress}

metabolic disorders, particularly diabetes. This journal is indexed on PubMed Central and MedLine. The manuscript management system is completely online and includes a very quick and fair peer-review system, which is all easy to use. Visit http://www.dovepress.com/ testimonials.php to read real quotes from published authors. 